\title{
Cryo-electron tomography of native Drosophila tissues vitrified by plunge freezing
}

\author{
Felix J.B. Bäuerlein ${ }^{1,2,3}$, José C. Pastor-Pareja ${ }^{4,5}$ and Rubén Fernández-Busnadiego $0^{1,2,3}$
}

${ }^{1}$ Department of Molecular Structural Biology, Max Planck Institute of Biochemistry, 82152 Martinsried, Germany. ${ }^{2}$ Institute of Neuropathology, University Medical Center Göttingen, 37099 Göttingen, Germany. ${ }^{3}$ Cluster of Excellence "Multiscale Bioimaging: from Molecular Machines to Networks of Excitable Cells" (MBExC), University of Göttingen, Germany. ${ }^{4}$ School of Life Sciences, Tsinghua University, Beijing 100084, China. ${ }^{5}$ Tsinghua-Peking Center for Life Sciences, Tsinghua University, Beijing 100084 , China.

Correspondence: baeuerlein@biochem.mpg.de (Felix J.B. Bäuerlein), josepastor@tsinghua.edu.cn (José C. Pastor-Pareja), ruben.fernandezbusnadiego@med.uni-goettingen.de (Rubén Fernández-Busnadiego)

Cryo-focused ion beam (cryo-FIB) milling allows thinning vitrified cells for high resolution imaging by cryo-electron tomography (cryo-ET). However, it remains challenging to apply this workflow to tissues, as they usually require high-pressure freezing for vitrification. Here we show that dissected Drosophila tissues can be directly vitrified by plunge freezing upon a short incubation in $10 \%$ glycerol. This expedites subsequent cryo-FIB/ET, enabling systematic analyses of the molecular architecture of native tissues.

C ryo-ET allows imaging the cell interior at molecular resolution (Wagner et al., 2017, Beck and Baumeister, 2016). This relies on the pristine preservation of cellular ultrastructure by vitrification (Dubochet and Sartori Blanc, 2001), which requires sufficiently fast cooling to prevent the re-organization of water molecules into crystalline ice (Dubochet et al., 1988). Cryo-FIB milling is currently the method of choice to thin down vitrified cells into electron-transparent lamellae (Rigort and Bäuerlein et al., 2012a, Marko et al., 2007, Strunk et al., 2012, Hayles et al., 2010) to enable high-quality cryo-ET imaging.

To date, cryo-FIB/ET has been applied mainly to isolated cells in culture (Wagner et al., 2017, Beck and Baumeister, 2016), which can in principle be conveniently vitrified by plunge freezing into a cryogen (Dubochet et al., 1988). Plunge frozen cells are embedded in a thin film of buffer or medium, and can thus be directly thinned down by cryo-FIB. In practice, however, most cultured mammalian cells are not fully vitrified by plunge freezing, as their core regions are too thick ( $10 \mu \mathrm{m}$ ) for efficient heat transfer (Mahamid et al., 2016). To achieve vitrification of specimens up to $\sim 200 \mu \mathrm{m}$-thick, it is possible to resort to high-pressure freezing (Studer et al., 2008). However, this results in specimens embedded in a thick block of ice that prevents direct cryoFIB milling, requiring complex procedures such as cryo-sectioning or cryo-lift out (Mahamid et al., 2015, Schaffer et al., 2019, Al-Amoudi, 2004, Hsieh et al., 2014, De Winter et al., 2021, Hayles et al., 2010). Furthermore, since no surface topography is visible in high-pressure frozen samples, the identification of target structures requires correlative light-microscopy. Altogether, the throughput of current cryo-ET tissue workflows is insufficient to address complex biological questions.

To achieve full vitrification of cultured cells, we routinely incubate them in a solution of $10 \%$ glycerol prior to plunge freezing (Bäuerlein et al., 2017). Morphological subtomogram averaging analyses indicate that glycerol treatment is not detrimental to cellular architecture (Bäuerlein et al., 2017, Guo et al., 2018). In fact, glycerol is a widely used cryo-protectant, as it substantially increases the glass transition temperature (John Morris et al., 2012) and has minimal influence on protein structure and cell function (Ye et al., 2006, Sousa, 1995). Glycerol is naturally produced by cells (Alves-Bezerra and Cohen, 2017, Zhang et al., 2018), and is commonly used in human medicine (Liu, 2011, Robergs and Griffin, 1998, Righetti et al., 2004). Furthermore, glycerol production is a well-documented adaptation to survive freezing winter temperatures in some insects and vertebrates (Zachariassen, 1985, Rexer-Huber et al., 2011). Here we show that a brief incubation in $10 \%$ glycerol is also sufficient to allow vitrification of native tissues dissected from third instar (L3) larvae of the fruit fly Drosophila melanogaster.

Drosophila is advantageous for cryo-FIB/ET because its organs are relatively small and can be conveniently dissected. First, we tested whether the Drosophila nervous system could be vitrified by plunge freezing. To that end, we dissected cephalic complexes, containing the central nervous system (CNS) and peripheral nerves. Isolated cephalic complexes were deposited on conventional carbon-coated EM grids and plunge frozen upon 2-5 min incubation in PBS with (Fig. $1 \mathrm{~g}-\mathrm{l}$ ) or without $10 \%$ glycerol (Fig. 1a-f). Visual examination by cryoFIB and cryo-scanning electron microscopy (cryo-SEM) revealed a high degree of anatomical detail (Fig. 1a, b, g, h), allowing direct identification of structures of interest. Initially we targeted the peripheral nerves, recognizable as long tubules projecting from the ventral nerve cord (VNC; Fig. 1a, b, g, h). The nerves were $\sim 15 \mu \mathrm{m}$ in diameter, and thus comparable in thickness to the perinuclear region of cultured mammalian cells. We prepared cryo-FIB lamellae of these regions using similar milling parameters as with cultured cells (Bäuerlein et al., 2017) (Fig. 1c, d, i, j), and inspected them by cryotransmission electron microscopy (cryo-TEM) imaging and diffraction analyses. Low magnification imaging of lamellae produced in the absence of glycerol revealed high-contrast Bragg reflections indicative of ice crystal formation (Fig. 1e). These features were striking in tomographic tilt series (Supplementary Video 1). Consistently, diffraction analysis of these lamellae showed spots and sharp rings characteristic of crystalline ice (Dubochet et al., 1988) (Fig. 1f). In contrast, lamellae produced from nerves incubated with glycerol had a smooth appearance at low and high magnifications (Fig. 1k, Supplementary Video 1). Furthermore, diffraction analysis (Fig. 1l) revealed diffuse rings characteristic of vitreous ice in these samples (Dubochet et al., 1988, Blackman and Lisgarten, 1997). Therefore, the cooling rates achieved by plunge freezing were sufficient to vitrify thin peripheral nerves with the aid of glycerol.

A common difficulty in cryo-FIB/ET is to visualize and subsequently target appropriate tomographic regions in low magnification lamella overviews. The contrast of these images is dominated by curtaining artifacts and thickness variations (Bäuerlein et al., 2017, Guo et al., 2018, Arnold et al., 2016) (Fig. 1e, k), arising from the different milling efficiency on different cellular components and the limited focus depth of the ion beam, respectively (Rigort and Bäuerlein et al., 2012a). Increasing image contrast makes these artifacts even more pronounced (Extended Data Fig. 1a, b). This is especially detrimental for analyzing cryo-FIB lamellae of tissues, given their rich biological complexity. To address this issue, we developed an algorithm termed 
bioRxiv preprint doi: https://doi.org/10.1101/2021.04.14.437159; this version posted April 14, 2021. The copyright holder for this preprint (which was not certified by peer review) is the author/funder, who has granted bioRxiv a license to display the preprint in perpetuity. It is made available under aCC-BY-NC-ND 4.0 International license.
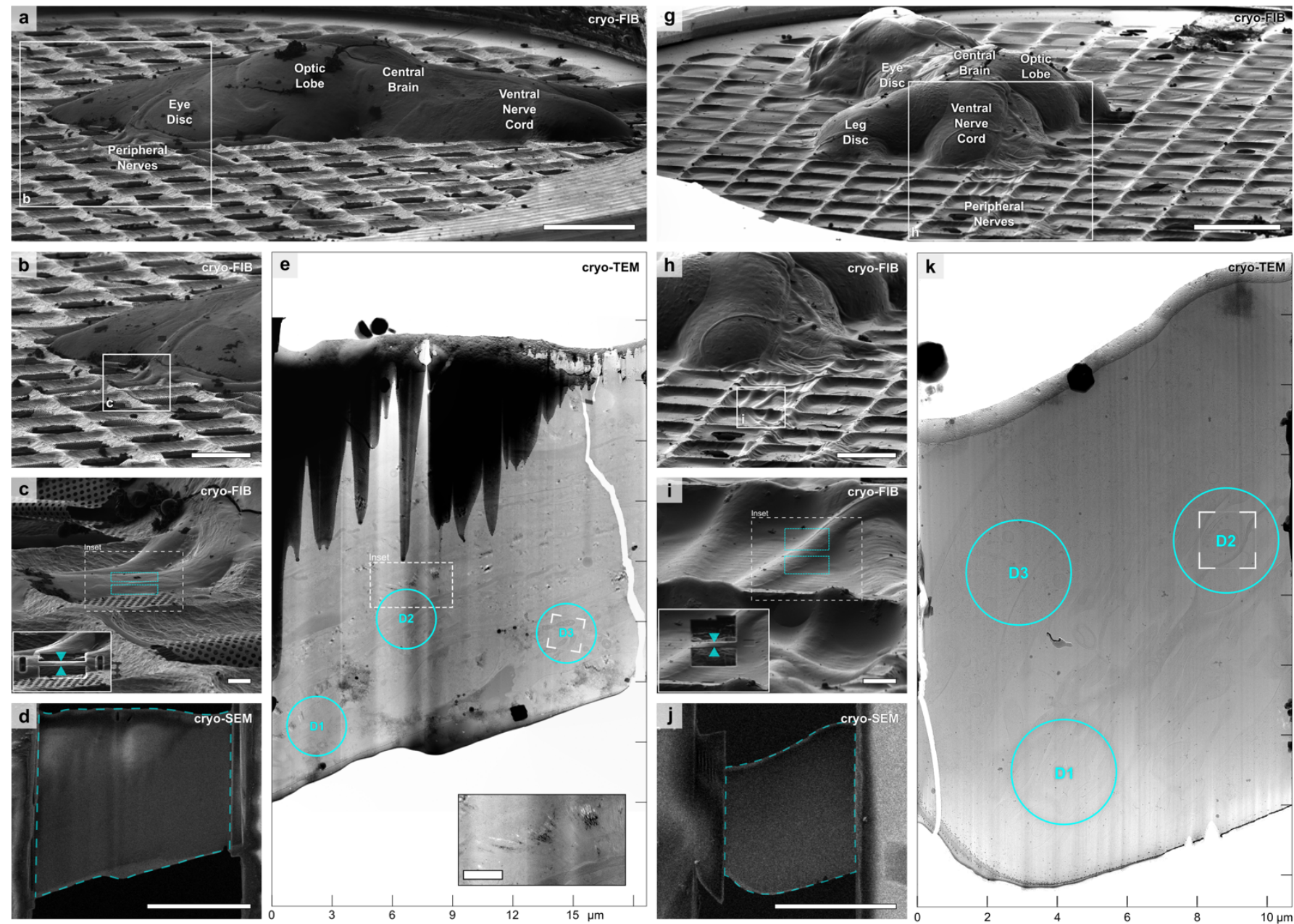

10.
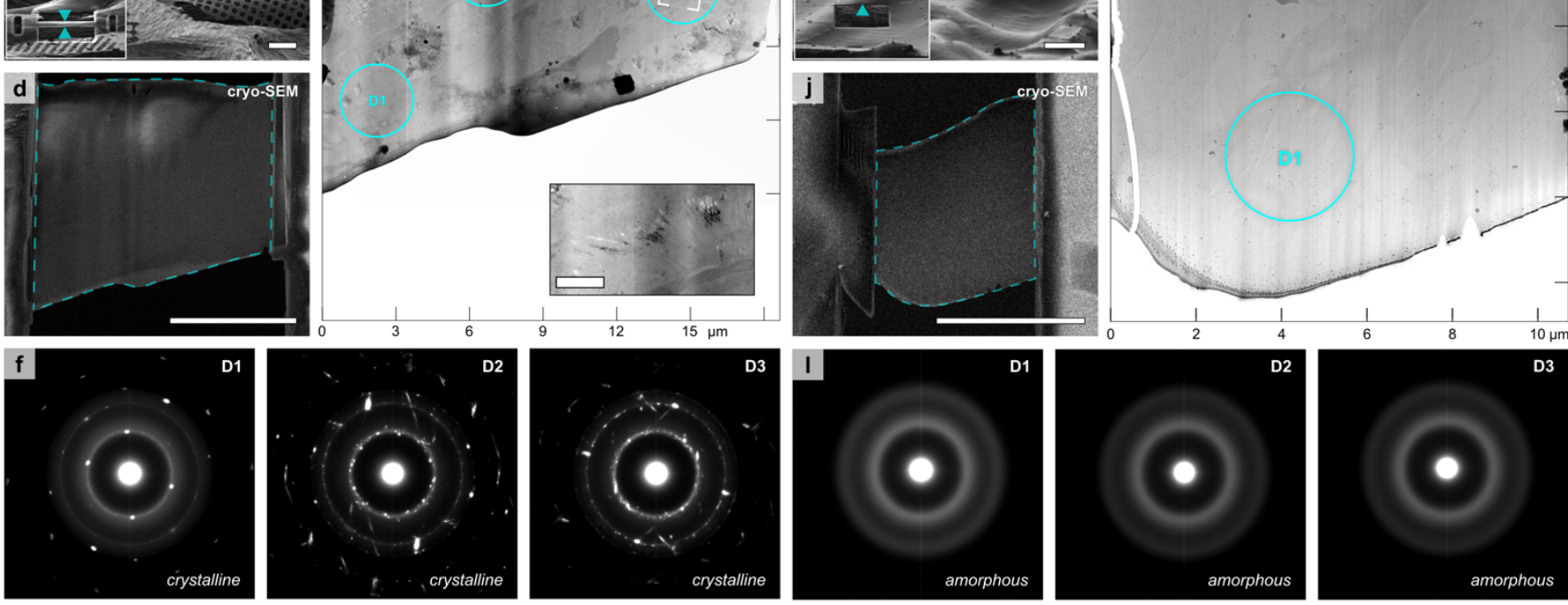

Fig. 1: Short incubation in $10 \%$ glycerol allows vitrification of Drosophila peripheral nerves by plunge freezing.

(a)-(f) Cryo-FIB lamella preparation and diffraction analysis of nervous tissue incubated 2-5 min in PBS only. (a) Cryo-FIB-induced secondary electron image of a cephalic complex $\left(1.2 \times 0.6 \times 0.2 \mathrm{~mm}^{3}\right)$, including the central nervous system, plunge frozen on an EM grid. (b) Magnification of the area boxed in (a) showing peripheral nerves emerging from the ventral nerve cord. (c) Magnification of the area boxed in (b). Blue rectangles indicate patterns for tissue removal by cryo-FIB milling. The inset shows the indicated region during lamella preparation (blue arrows). (d) Top view cryo-SEM image of the final lamella shown in (c). The blue line indicates the lamella area shown in (e). (e) Cryo-TEM overview of the final lamella shown in $(c, d)$. Blue circles indicate the regions where vitrification was assessed by electron diffraction ( $f$ ). The inset shows a magnification of the region boxed in the main panel with a white broken line. This region shows artifacts (black/white Bragg reflections) caused by diffraction of the electron beam in crystalline ice. The box within D3 marks the area where the tilt series shown in Supplementary Video 1 (left) was recorded. (f) Diffraction patterns recorded on the regions D1-D3 marked in (e), showing predominantly crystalline ice, even close to the lamella surface (D1).

(g)-(I) Cryo-FIB lamella preparation and diffraction analysis of nervous tissue incubated 2-5 min in PBS with $10 \%$ glycerol. (g) Cryo-FIB-induced secondary electron image of a

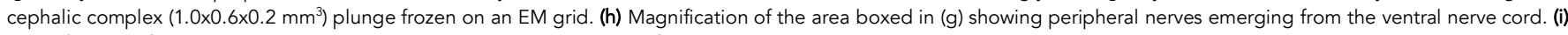
Magnification of the area boxed in ( $h$ ). Blue rectangles indicate patterns for tissue-removal by cryo-FIB milling. The inset shows the indicated region during lamella preparation (blue arrows). (j) Top view cryo-SEM image of the final lamella shown in (i). The blue line indicates the lamella area shown in (k). (k) Cryo-TEM overview of the final lamella shown in $(i, j)$. Blue circles indicate regions where vitrification was assessed by electron-diffraction (I). The lamella appears smooth, without artifacts induced by diffraction of the electron beam in crystalline ice. The box within D2 marks the area where the tilt series shown in Supplementary Video 1 (right) was recorded. (I) The diffraction patterns of the regions D1D3 marked in ( $k$ ) show diffuse rings characteristic of vitreous ice throughout the complete lamella.

Scale bars: $200 \mu \mathrm{m}(a, g), 100 \mu \mathrm{m}$ in (b, h), $10 \mu \mathrm{m}(c, d, i, j), 1 \mu \mathrm{m}$ (e, inset).

LisC ("Lamella in silico Clearing") to remove obscuring features from lamella overviews. First, a high-pass filter is applied to remove the low frequency brightness modulation caused by long-range thickness variations (Extended Data Fig. 1c, d). Then, a line filter is applied in Fourier space to remove line artifacts caused by curtaining (Extended Data Fig. 1e, f). This results as well in the formation of ringing artifacts near high-contrast features, such as ice crystal contamination or the vacuum background (Extended Data Fig. 1e). However, when these features are masked by a local gray value average (Extended Data Fig. $1 \mathrm{~h})$, ringing artifacts are minimized and Fourier line filtering results in high-contrast images where the structural features of the lamella can be clearly discerned (Extended Data Fig. 1g, Supplementary Video 2).

We next examined lamellae of vitrified glycerol-treated nerves by cryo-ET. LisC filtering of lamella overview images allowed selecting areas for cryo-ET data collection based on a detailed histological analysis (Fig. 2b, Extended Data Fig. 2e). Cryo-ET revealed an excellent preservation of cell morphology (Fig. 2c-d), consistent with our previous studies in glycerol-treated cultured cells (Bäuerlein et al., 2017, Guo et al., 2018). Importantly, tomograms of vitrified nerves showed molecular details of tissue-specific structures that cannot be 
bioRxiv preprint doi: https://doi.org/10.1101/2021.04.14.437159; this version posted April 14, 2021. The copyright holder for this preprint (which was not certified by peer review) is the author/funder, who has granted bioRxiv a license to display the preprint in perpetuity. It is made available under aCC-BY-NC-ND 4.0 International license.
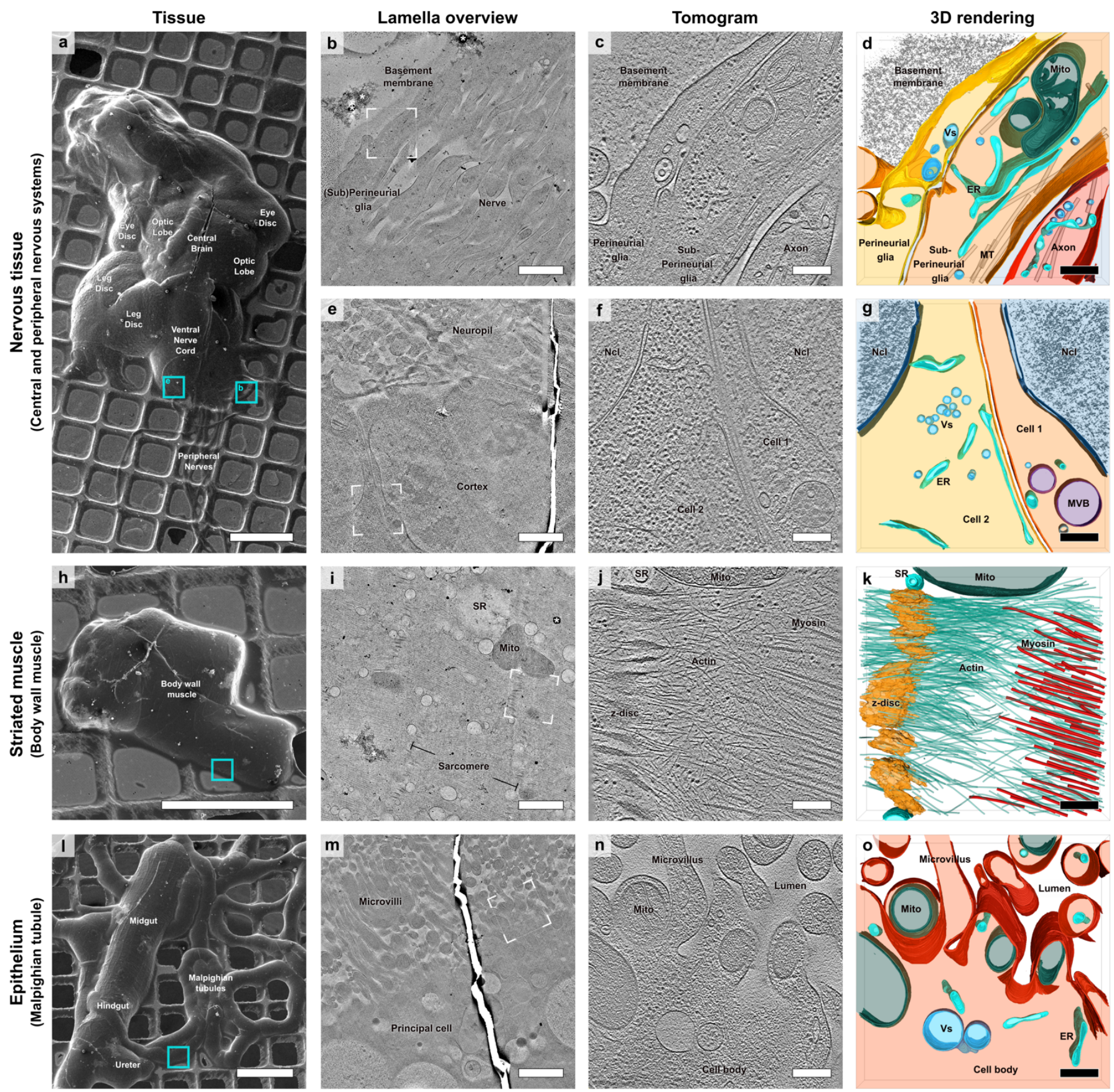

Fig. 2: Gallery of Drosophila tissues analyzed by cryo-FIB/ET upon vitrification by plunge freezing.

Rows represent different tissue types, and columns show different visualizations: cryo-SEM (first column), cryo-TEM lamella overviews filtered by the LisC algorithm (second column), cryo-ET slices (third column) and 3D renderings (fourth column).

(a)-(d) Peripheral nervous system (peripheral nerve). (a) Top view cryo-SEM image of Drosophila cephalic complex shown in Fig. 1g. Anatomical features can be directly observed and are annotated. Blue boxes indicate regions of lamella preparation of the peripheral (b) and central (e) nervous system. (b) Cryo-TEM overview of a lamella prepared in the area marked in (a) on a peripheral nerve (see also Extended Data Fig. 2). The lamella contains multiple axons, together with sub-perineurial and perineurial glial cells and a basement membrane wrapping the nerve. * mark crystalline ice contamination deposited on top of the lamella. (c) $1.7 \mathrm{~nm}$-thick slice of a tomogram recorded in the area marked in (b), showing an axon, the sub-perineurial and perineurial glia and the basement membrane. (d) $3 \mathrm{D}$ rendering of the tomogram in (c). Warm colors represent different cells, cold colors represent subcellular structures: axon (red), sub-perineurial glia (orange), perineurial glia (yellow), basement membrane (gray), interstitial space (transparent light blue), endoplasmic reticulum (ER, turquoise), mitochondria (Mito, dark green), microtubules (MT, transparent gray), vesicles (Vs, light blue). See also Supplementary Video 3.

(a, e-g) Central nervous system (VNC cortex). (e) Cryo-TEM overview of a lamella prepared in the area marked in (a). Cell bodies can be seen in the bottom part of the image, while the neuropil is visible on the top. (f) $1.7 \mathrm{~nm}$-thick slice of a tomogram recorded in the area marked in (e) showing two adjacent cells of the ventral nerve cord. Ncl: nucleus. (g) 3D rendering of the tomogram shown in (f). Cell 1 (orange), cell 2 (yellow), nucleus ( $\mathrm{Ncl}$, dark blue), endoplasmic reticulum (ER, turquoise), multi vesicular bodies (MVB, violet), vesicles (Ns, light blue). See also Supplementary Video 4.

(h)-(k) Striated muscle (body wall muscle). (h) Top view cryo-SEM image of a body wall muscle from an abdominal segment. A blue box indicates the region targeted for lamella preparation. (i) Cryo-TEM overview of a lamella prepared in the area marked in (h). The lamella shows the sarcomeres, the sarcoplasmic reticulum (SR) and mitochondria (Mito). (j) $1.7 \mathrm{~nm}$-thick slice of a tomogram recorded in the area marked in (i), showing the interplay of myosin and actin filaments associated to the z-disc. (k) 3D rendering of the tomogram in (j). Myosin fibrils (red), actin fibrils (green), z-disc (yellow), sarcoplasmic reticulum (SR, turquoise), mitochondria (Mito, dark green). See also Supplementary Video 5. (I)-(o) Epithelium (Malpighian tubule). (I) Top view cryo-SEM image of the Malpighian tubules, associated via the ureter to the gut. A blue box indicates the region targeted for lamella preparation. $(\mathrm{m})$ Cryo-TEM overview of a lamella prepared in the area marked in (I). The lamella shows the luminal side of a principal cell body of the Malpighian tubule, with the cell body in the lower part of the image and the microvilli ranging into the tubule lumen in the top (see also Extended Data Fig. 3). ( $\mathrm{n}$ ) $1.7 \mathrm{~nm}$-thick slice of a tomogram recorded in the area marked in ( $\mathrm{m}$ ), showing the luminal side of the principal cell. Mito: mitochondrion. (o) 3D rendering of the tomogram shown in (n). Principal cell (red), endoplasmic reticulum (ER, turquoise), mitochondria (Mito, dark green), vesicles (Vs, light blue). See also Supplementary Video 6.

Scale bars: $200 \mu \mathrm{m}(a, h, l), 1.5 \mu \mathrm{m}(b, e, i, m), 250 \mathrm{~nm}(c, d, f, g, j, k, n, o)$. 
bioRxiv preprint doi: https://doi.org/10.1101/2021.04.14.437159; this version posted April 14, 2021. The copyright holder for this preprint (which was not certified by peer review) is the author/funder, who has granted bioRxiv a license to display the preprint in perpetuity. It is made available under aCC-BY-NC-ND 4.0 International license.

reproduced in culture, such as the wrapping of axons by perineurial glia or the intricate architecture of the basement membrane (Fig. 2c, d, Supplementary Video 3). It was routinely possible to record multiple tomograms within one lamella, providing a broad overview of different regions of the tissue (Extended Data Fig. 2). These data indicate that peripheral nerves $\sim 15 \mu \mathrm{m}$ in diameter can be vitrified by plunge freezing upon a brief incubation in glycerol, allowing direct cryo-ET analysis of native tissue architecture.

However, other Drosophila tissues are substantially thicker than peripheral nerves, which may complicate vitrification and cryo-FIB milling. Therefore, we investigated whether superficial regions of the CNS ( 200 $\mu \mathrm{m}$ thick) could also be vitrified by plunge freezing in 10\% glycerol. We prepared cryo-FIB lamellae of the VNC cortical region (Fig. 2a, e) using a 5-10 fold higher ion beam current to efficiently remove large amounts of material during the initial milling step. CryoET imaging of the resulting lamellae revealed smooth membranes and high density of cytosolic macromolecules, with no signs of crystalline ice (Fig. 2e-g, Supplementary Video 4). Thus, glycerol incubation also allowed vitrification and cryo-ET imaging of superficial regions of the CNS.

To explore whether our approach was also applicable beyond nervous tissue, we examined body wall muscles. Dissected muscles with attached innervations were also directly amenable to direct cryoET imaging upon cryo-FIB milling (Fig. 2h-k). Low magnification images showed sarcomeres intercalated with mitochondria and the sarcoplasmic reticulum (Fig. 2i). Cryo-ET analysis of the sarcomere revealed the detailed organization of thick and thin filaments, as well as their connection to the Z-disk (Fig. 2j, k, Supplementary Video 5). Therefore, our approach allows imaging at molecular resolution complete neuromuscular circuits of Drosophila larvae, from the neuronal cell bodies in the VNC (Fig. 2a, e-g), their axonal projections forming the peripheral nerves (Fig. 2a-d) to the body wall muscles they innervate (Fig. 2h-k).

As an example of epithelial tissue, we investigated the Malpighian tubules, functional equivalent of the vertebrate kidney. Plunge-frozen dissected Malpighian tubules were directly milled by cryo-FIB (Fig. 2lo). Lamellae overviews and cryo-tomograms showed the exquisite complexity of this polarized tissue, from the basal system of labyrinth channels to the apical microvilli (Fig. 2l-o, Extended Data Fig. 3, Supplementary Video 6). Occasionally, crystalline ice was observed in the tubule lumen, where the lower solute concentration provides lower cryo-protection, but not within the cell interior. Therefore, a short incubation in $10 \%$ glycerol allows vitrification of superficial areas of nervous, muscle and epithelial Drosophila tissues by plunge freezing, greatly facilitating subsequent cryo-FIB milling and cryo-ET imaging. Our method is also fully compatible with correlative cryo-light microscopy, although it is possible to target anatomical regions of interest directly by cryo-SEM imaging.

Our approach provides the first cryo-ET visualizations of unique tissue features that cannot be reproduced in culture, enabling detailed examination of full functional circuits. Drosophila offers an extraordinary breadth of genetic tools to study basic biological mechanisms and model human disease (Bilder and Irvine, 2017, Ugur et al., 2016). Thus, we anticipate that the method presented here will allow addressing in situ the structural basis of a broad variety of biological phenomena. Since this method is limited to relatively small tissues, other techniques (Schaffer et al., 2019) remain valuable to study thicker tissue depths. On the other hand, our approach is not intrinsically limited to Drosophila, and could also allow direct cryoFIB/ET of, e.g., organoids, thin dissected mammalian tissues (Heuser and Tenkova, 2020) or even human biopsies.

\section{Methods}

\section{Drosophila breeding, dissection and plunge freezing}

Fly cultures were grown at $25^{\circ} \mathrm{C}$ in standard fly medium. Assorted tissues from third instar larvae (L3 stage) of the wild type Canton-S strain were dissected during 2-5 min in PBS (Thermo Fisher) with or without $10 \%$ glycerol after turning larvae inside out with the help of fine tip forceps. Dissections were performed under a Leica S6E stereomicroscope. Dissected tissues were placed on 200 mesh Molybdenum R2/1 EM grids (Quantifoil) immediately after dissection. The grids were subsequently mounted on a manual plunger, blotted from the back side using Whatman paper \#1 (Sigma-Aldrich) and plunged into a 2:1 ethane:propane mixture cooled down by liquid nitrogen.

\section{Cryo-FIB milling}

To prepare thin electron transparent lamellae into the tissue, plungefrozen grids were first mounted into Autogrid frames (FEI). The grids were then mounted into a dual-beam Quanta 3D FIB/SEM (FEI) using a custom-built transfer shuttle and a cryo-transfer system (PP3000T, Quorum). The samples were kept at $-180^{\circ} \mathrm{C}$ throughout FIB milling by the cryo-stage. To improve SEM imaging, a thin layer of pure metallic Pt was sputtered onto the sample under cryo conditions in the PP3000T transfer system to increase electrical conductivity. The following parameters were used: $10 \mathrm{~mA}$ sputtering current, $500 \mathrm{~V}$ between stage and sputtering target and $30 \mathrm{~s}$ of exposure at $4.5 \times 10^{-2}$ mbar. To interpret and annotate the topographical anatomy of the tissue, overview maps of the EM grid were acquired by SEM at $10 \mathrm{kV}$ at 100-250x magnification (object pixel size 1.1-0.4 $\mu \mathrm{m}$ ) and by secondary electrons induced by the $\mathrm{Ga}^{+}$focused ion beam at $30 \mathrm{kV}$ and 338x magnification (object pixel size $0.7 \mu \mathrm{m}$ ). To protect the milling front of the lamellae, gaseous organic platinum was frozen on top of the grid using a gas injection system. To prevent bending of the lamella during the preparation, micro-expansion joints were milled left and right of the intended lamella preparation site (Wolff et al., 2019). 10-20 $\mu \mathrm{m}$ wide lamellae were prepared into the tissue with the ion beam at $30 \mathrm{kV}$ at shallow angles $\left(8-14^{\circ}\right)$ in four consecutive steps: for the thicker tissue regions (e.g. VNC or skeletal muscle), the areas above and below the intended lamella were first removed with an ion beam current of $5 \mathrm{nA}$ and $10 \mu \mathrm{m}$ spacing. This step was not necessary for thinner tissues such as the peripheral nerves. Further rectangular patterns were defined above and below the intended lamella with 2 $\mu \mathrm{m}$ spacing for the rough milling step (ion beam current of 500-1000 $\mathrm{pA})$, followed by fine milling with $800 \mathrm{~nm}$ spacing (100 pA) and a final polishing step down to the final lamella thickness of 100-200 nm (50 pA). To reach a uniform thickness, the lamella was tilted by $\pm 0.5^{\circ}$ and milled on each side separately with $50 \mathrm{pA}$ current. The thickness of the lamella during the polishing step was assessed by SEM at 3-5 kV, 4.1 $\mathrm{pA}$ : vanishing of bright (charged) areas of the lamella indicated a thickness of $<300 \mathrm{~nm}$ at $5 \mathrm{kV}$ or $<200 \mathrm{~nm}$ at $3 \mathrm{kV}$. Biological structures inside the lamella at the surface were imaged at each step by SEM at $2.5 \mathrm{kV}$, and4.1 pA in integration mode (64x). To reduce lamella charging during phase plate cryo-ET data acquisition, a thin layer of pure metallic Pt was sputtered onto the lamella under cryo conditions in the PP3000T transfer system with the following parameters: $5 \mathrm{~mA}$ sputtering current, $500 \mathrm{~V}$ between stage and sputtering target and 10 $\mathrm{s}$ of exposure at $4.5 \times 10^{-2} \mathrm{mbar}$.

\section{Cryo-TEM imaging and diffraction}

Cryo-FIB lamellae were imaged using a Titan Krios cryo-TEM (FEI) equipped with a field emission gun operated at $300 \mathrm{kV}$, a Volta phase (Danev et al., 2014), a post-column energy filter (Gatan) operated at zero-loss and a K2 Summit direct electron detector (Gatan). Low magnification projections of lamellae were recorded (11.500 $x$, object pixel size 1.312 nm for Fig. 2m and Extended Data Fig. 3e; 4.800 , object pixel size $3.064 \mathrm{~nm}$ for all other lamella overviews) using the montage option in SerialEM (Mastronarde, 2005) (RRID:SCR_017293) with $15 \%$ overlap and $-20 \mu \mathrm{m}$ defocus. Phase plate alignment and 
bioRxiv preprint doi: https://doi.org/10.1101/2021.04.14.437159; this version posted April 14, 2021. The copyright holder for this preprint (which was not certified by peer review) is the author/funder, who has granted bioRxiv a license to display the preprint in perpetuity. It is made available under aCC-BY-NC-ND 4.0 International license.

operation was carried out as described (Fukuda et al., 2015). Upon phase plate conditioning, high magnification $(33,000 x$, object pixel size $0.421 \mathrm{~nm}$ ) tilt series were recorded at locations of interest using the SerialEM low dose acquisition scheme with a tilt increment of $2^{\circ}$, typically spanning an angular range from $-60+\xi^{\circ}$ to $+60+\xi^{\circ}$, where $\xi$ is the pre-tilt of the lamella $\left(\sim+13^{\circ}\right)$. Target defocus was set to $-0.5 \mu \mathrm{m}$. The K2 camera was operated in dose fractionation mode recording frames every $0.2 \mathrm{~s}$. For each tilt series, a new spot on the phase plate was selected. The total dose was limited to $100-150 \mathrm{e}^{-/} / \AA^{2}$. Diffraction patterns were acquired of the indicated regions with the same beam settings as for tomography, a selected area of $7 \mu \mathrm{m}^{2}$, a camera length of $1.95 \mathrm{~m}$ and a total dose of $10 \mathrm{e}^{-/} / \AA^{2}$.

\section{Data analysis}

\section{Tomogram reconstruction and segmentation}

Raw K2 camera frames were aligned using MotionCor2 (Zheng et al., 2017) (RRID:SCR_016499). The resulting tilt series were aligned using patch tracking in version 4.7 of the IMOD package (Kremer et al., 1996) (RRID:SCR_003297) and reconstructed by weighted back projection. For tomographic reconstruction, a radial filter with the following values was applied: cut-off: 0.35, fall-off: 0.05. Membranes were first automatically segmented using the TomoSegMemTV package (Martinez-Sanchez et al., 2014) and refined manually and visualized using Amira (FEI Visualization Sciences Group; RRID:SCR_014305). Microtubules and the sarcomeric cytoskeleton were automatically detected using the XTracing Module in Amira (Rigort et al., 2012b).

\section{Stitching of low magnification projections for lamella overviews}

Low magnification images of lamellae were stitched using the Image Composite Editor (Microsoft Research) to produce complete overviews. Image tiles were imported using the option "Structured Panorama". The camera motion was defined to "Planar motion", the image order "Zigzag", the angular range to "Less than $360^{\circ}$ ", the overlap according to the parameter set in the montage menu of SerialEM and the search radius $5 \%$ more than the overlap. After the stitching procedure, the lamella was rotated so that the curtains were vertically aligned, and the overviews were cropped and saved.

\section{Lamella in-silico Clearing ( $\mathrm{LisC}$ ) filter}

The LisC algorithm was programmed as macro for Fiji (Schindelin et al., 2012) (RRID:SCR_002285) and is publicly available (https://github.com/FJBauerlein/LisC_Algorithm). The input for the macro are the stitched lamella overview image and its pixel size. First, the image is high-pass filtered to remove the low frequency brightness modulations caused by long-range thickness variations. For this, the Fiji function "Bandpass filter" is used with the cut-off values of 1 pixel and $5 \mu \mathrm{m} /$ pixel size. Then, masks for regions of extreme contrast (e.g. ice crystal contamination and vacuum) are created to avoid ringing artifacts caused by filtering in Fourier space. For that, thresholds for the contamination (default: mean - 1.5xSD) and vacuum (default: mean $+1.5 \times \mathrm{SD}$ ) regions are set. The masks are then applied on the original image and the pixel values of the masked regions are substituted by a local gray value average obtained by a Gaussian blur filter with a sigma of $5 \mu \mathrm{m}$ divided by the pixel size. Then, the line artifacts caused by curtaining are removed by a line filter, where the line in Fourier space is placed perpendicular to the line artifacts in real space. This is applied by the Fiji function "Suppress stripes" with a tolerance of direction of $95 \%$. The Fourier filtering also causes gray values changes of the contamination and vacuum regions defined by the mask. Therefore, the pixel values in those regions are set to 0 (contamination) and 256 (vacuum), respectively.

\section{Data availability}

The tomograms shown in Fig. 2 are available at EMDB with the following accession codes: EMD-12726 (Fig. 2c, d), EMD-12727 (Fig. 2f, g), EMD-12728 (Fig. 2j, k) and EMD-12729 (Fig. 2n, o).

\section{Code availability}

The Lis $C$ algorithm is available at: https://github.com/FJBauerlein/LisC Algorithm.

\section{Acknowledgments}

We thank Nicolas Gompel and Bettina Mühling for providing Drosophila cultures. We thank Wolfgang Baumeister and Jürgen Plitzko for providing access to electron microscopy infrastructure, stimulating discussions and the critical reading of this manuscript. We thank Philipp Erdmann and Miroslava Schaffer for electron microscopy support. F.J.B.B. and R.F.-B. acknowledge funding from the Deutsche Forschungsgemeinschaft (DFG, German Research Foundation) through Germany's Excellence Strategy - EXC 2067/1- 390729940. J.C.P.-P. acknowledges funding from Natural Science Foundation of China (NSFC) grants 91854207 and 31771600.

\section{Author contributions}

F.J.B.B. , J.C.P.-P. and R.F.-B. planned research. J.C.P.-P. performed Drosophila dissections. F.J.B.B. vitrified samples and performed cryoFIB and cryo-ET. F.J.B.B. analyzed the data. J.C.P.-P. and R.F.-B. supervised electron microscopy experiments and data analysis. F.J.B.B., J.C.P.-P. and R.F.-B. wrote the manuscript.

\section{Competing interests}

The authors declare no competing interests.

\section{Additional information}

Supplementary Information is available for this paper.

Correspondence and requests for materials should be addressed to F.J.B.B. (baeuerlein@biochem.mpg.de),

J.C.P.-P. (josepastor@tsinghua.edu.cn),

R.F.-B. (ruben.fernandezbusnadiego@med.uni-goettingen.de). 
bioRxiv preprint doi: https://doi.org/10.1101/2021.04.14.437159; this version posted April 14, 2021. The copyright holder for this preprint (which was not certified by peer review) is the author/funder, who has granted bioRxiv a license to display the preprint in perpetuity. It is made available under aCC-BY-NC-ND 4.0 International license.

\section{References}

AL-AMOUDI, A. C. J., LEFORESTIER A, MCDOWALL A, SALAMIN LM, NORLÉN LP, RICHTER K, BLANC NS, STUDER D, DUBOCHET J 2004. Cryoelectron microscopy of vitreous sections. EMBO J, 23, 3583-8.

ALVES-BEZERRA, M. \& COHEN, D. E. 2017. Triglyceride Metabolism in the Liver. Compr Physiol, 8, 1-8.

ARNOLD, J., MAHAMID, J., LUCIC, V., DE MARCO, A., FERNANDEZ, J. J., LAUGKS, T., MAYER, T., HYMAN, A. A., BAUMEISTER, W. \& PLITZKO, J. M. 2016. Site-Specific Cryo-focused Ion Beam Sample Preparation Guided by 3D Correlative Microscopy. Biophys J, 110, 860-9.

BÄUERLEIN, F. J. B., SAHA, I., MISHRA, A., KALEMANOV, M., MARTINEZSANCHEZ, A., KLEIN, R., DUDANOVA, I., HIPP, M. S., HARTL, F. U. BAUMEISTER, W. \& FERNANDEZ-BUSNADIEGO, R. 2017. In Situ Architecture and Cellular Interactions of PolyQ Inclusions. Cell, 171 179-187 e10

BECK, M. \& BAUMEISTER, W. 2016. Cryo-Electron Tomography: Can it Reveal the Molecular Sociology of Cells in Atomic Detail? Trends Cell Biol, 26, 825-837.

BILDER, D. \& IRVINE, K. D. 2017. Taking Stock of the Drosophila Research Ecosystem. Genetics, 206, 1227-1236.

BLACKMAN, M. \& LISGARTEN, N. D. 1997. The cubic and other structural forms of ice at low temperature and pressure. Proceedings of the Royal Society of London. Series A. Mathematical and Physical Sciences, 239, 93-107

DANEV, R., BUIJSSE, B., KHOSHOUEI, M., PLITZKO, J. M. \& BAUMEISTER, W. 2014. Volta potential phase plate for in-focus phase contrast transmission electron microscopy. Proc Natl Acad Sci U S A, 111 15635-40.

DE WINTER, D. A. M., HSIEH, C., MARKO, M. \& HAYLES, M. F. 2021. Cryo-FIB preparation of whole cells and tissue for cryo-TEM: use of highpressure frozen specimens in tubes and planchets. J Microsc, 281, 125-137.

DUBOCHET, J., ADRIAN, M., CHANG, J. J., HOMO, J. C., LEPAULT, J., MCDOWALL, A. W. \& SCHULTZ, P. 1988. Cryo-electron microscopy of vitrified specimens. Q Rev Biophys, 21, 129-228.

DUBOCHET, J. \& SARTORI BLANC, N. 2001. The cell in absence of aggregation artifacts. Micron, 32, 91-9.

FUKUDA, Y., LAUGKS, U., LUCIC, V., BAUMEISTER, W. \& DANEV, R. 2015 Electron cryotomography of vitrified cells with a Volta phase plate. $J$ Struct Biol, 190, 143-54.

GUO, Q., LEHMER, C., MARTINEZ-SANCHEZ, A., RUDACK, T., BECK, F., HARTMANN, H., PEREZ-BERLANGA, M., FROTTIN, F., HIPP, M. S. HARTL, F. U., EDBAUER, D., BAUMEISTER, W. \& FERNANDEZBUSNADIEGO, R. 2018. In Situ Structure of Neuronal C9orf72 PolyGA Aggregates Reveals Proteasome Recruitment. Cell, 172, 696-705 e12.

HAYLES, M. F., DE WINTER, D. A., SCHNEIJDENBERG, C. T., MEELDIJK, J. D. LUECKEN, U., PERSOON, H., DE WATER, J., DE JONG, F., HUMBEL, B. M. \& VERKLEIJ, A. J. 2010. The making of frozenhydrated, vitreous lamellas from cells for cryo-electron microscopy. J Struct Biol, 172, 180-90.

HEUSER, J. E. \& TENKOVA, T. I. 2020. Introducing a mammalian nerve-muscle preparation ideal for physiology and microscopy, the transverse auricular muscle in the ear of the mouse. Neuroscience, 439, 80-105.

HSIEH, C., SCHMELZER, T., KISHCHENKO, G., WAGENKNECHT, T. \& MARKO, M. 2014. Practical workflow for cryo focused-ion-beam milling of tissues and cells for cryo-TEM tomography. J Struct Biol, 185, 32-41.

JOHN MORRIS, G., ACTON, E., MURRAY, B. J. \& FONSECA, F. 2012. Freezing injury: the special case of the sperm cell. Cryobiology, 64, 71-80.

KREMER, J. R., MASTRONARDE, D. N. \& MCINTOSH, J. R. 1996. Computer visualization of three-dimensional image data using IMOD. J Struct Biol, 116, 71-6

LIU, L. W. 2011. Chronic constipation: current treatment options. Can J Gastroenterol, 25 Suppl B, 22B-28B.

MAHAMID, J., PFEFFER, S., SCHAFFER, M., VILLA, E., DANEV, R., CUELLAR, L. K., FORSTER, F., HYMAN, A. A., PLITZKO, J. M. \& BAUMEISTER, W. 2016. Visualizing the molecular sociology at the HeLa cell nuclear periphery. Science, 351, 969-72

MAHAMID, J., SCHAMPERS, R., PERSOON, H., HYMAN, A. A., BAUMEISTER, W. \& PLITZKO, J. M. 2015. A focused ion beam milling and lift-out approach for site-specific preparation of frozen-hydrated lamellas from multicellular organisms. J Struct Biol, 192, 262-9.
MARKO, M., HSIEH, C., SCHALEK, R., FRANK, J. \& MANNELLA, C. 2007. Focused-ion-beam thinning of frozen-hydrated biological specimens for cryo-electron microscopy. Nat Methods, 4, 215-7.

MARTINEZ-SANCHEZ, A., GARCIA, I., ASANO, S., LUCIC, V. \& FERNANDEZ, J. J. 2014. Robust membrane detection based on tensor voting for electron tomography. J Struct Biol, 186, 49-61.

MASTRONARDE, D. N. 2005. Automated electron microscope tomography using robust prediction of specimen movements. J Struct Biol, 152, 36-51.

REXER-HUBER, K. M., BISHOP, P. J. \& WHARTON, D. A. 2011. Skin ice nucleators and glycerol in the freezing-tolerant frog Litoria ewingii. $J$ Comp Physiol B, 181, 781-92.

RIGHETTI, E., CELANI, M. G., CANTISANI, T., STERZI, R., BOYSEN, G. \& RICCI, S. 2004. Glycerol for acute stroke. Cochrane Database Syst Rev 2004, CD000096.

RIGORT, A. \& BÄUERLEIN, F. J., VILLA, E., EIBAUER, M., LAUGKS, T., BAUMEISTER, W. \& PLITZKO, J. M. 2012a. Focused ion beam micromachining of eukaryotic cells for cryoelectron tomography. Proc Natl Acad Sci U S A, 109, 4449-54.

RIGORT, A., GUNTHER, D., HEGERL, R., BAUM, D., WEBER, B., PROHASKA, S. MEDALIA, O., BAUMEISTER, W. \& HEGE, H. C. 2012b. Automated segmentation of electron tomograms for a quantitative description of actin filament networks. J Struct Biol, 177, 135-44.

ROBERGS, R. A. \& GRIFFIN, S. E. 1998. Glycerol. Biochemistry, pharmacokinetics and clinical and practical applications. Sports Med 26, 145-67.

SCHAFFER, M., PFEFFER, S., MAHAMID, J., KLEINDIEK, S., LAUGKS, T. ALBERT, S., ENGEL, B. D., RUMMEL, A., SMITH, A. J., BAUMEISTER, W. \& PLITZKO, J. M. 2019. A cryo-FIB lift-out technique enables molecular-resolution cryo-ET within native Caenorhabditis elegans tissue. Nat Methods, 16, 757-762.

SCHINDELIN, J., ARGANDA-CARRERAS, I., FRISE, E., KAYNIG, V., LONGAIR, M., PIETZSCH, T., PREIBISCH, S., RUEDEN, C., SAALFELD, S. SCHMID, B., TINEVEZ, J. Y., WHITE, D. J., HARTENSTEIN, V., ELICEIRI, K., TOMANCAK, P. \& CARDONA, A. 2012. Fiji: an opensource platform for biological-image analysis. Nat Methods, 9, 67682

SOUSA, R. 1995. Use of glycerol, polyols and other protein structure stabilizing agents in protein crystallization. Acta Crystallogr D Biol Crystallogr $51,271-7$.

STRUNK, K. M., WANG, K., KE, D., GRAY, J. L. \& ZHANG, P. 2012. Thinning of large mammalian cells for cryo-TEM characterization by cryo-FIB milling. J Microsc, 247, 220-7.

STUDER, D., HUMBEL, B. M. \& CHIQUET, M. 2008. Electron microscopy of high pressure frozen samples: bridging the gap between cellula ultrastructure and atomic resolution. Histochem Cell Biol, 130, 87789.

UGUR, B., CHEN, K. \& BELLEN, H. J. 2016. Drosophila tools and assays for the study of human diseases. Dis Model Mech, 9, 235-44.

WAGNER, J., SCHAFFER, M. \& FERNANDEZ-BUSNADIEGO, R. 2017. Cryoelectron tomography-the cell biology that came in from the cold. FEBS Lett, 591, 2520-2533.

WOLFF, G., LIMPENS, R., ZHENG, S., SNIJDER, E. J., AGARD, D. A., KOSTER, A. J. \& BARCENA, M. 2019. Mind the gap: Micro-expansion joints drastically decrease the bending of FIB-milled cryo-lamellae. J Struct Biol, 208, 107389

YE, J. H., ZHANG, J., XIAO, C. \& KONG, J. Q. 2006. Patch-clamp studies in the CNS illustrate a simple new method for obtaining viable neurons in rat brain slices: glycerol replacement of $\mathrm{NaCl}$ protects $\mathrm{CNS}$ neurons. J Neurosci Methods, 158, 251-9.

ZACHARIASSEN, K. E. 1985. Physiology of cold tolerance in insects. Physiol Rev 65, 799-832.

ZHANG, X., YANG, S., CHEN, J. \& SU, Z. 2018. Unraveling the Regulation of Hepatic Gluconeogenesis. Front Endocrinol (Lausanne), 9, 802.

ZHENG, S. Q., PALOVCAK, E., ARMACHE, J. P., VERBA, K. A., CHENG, Y. \& AGARD, D. A. 2017. MotionCor2: anisotropic correction of beaminduced motion for improved cryo-electron microscopy. Nat Methods, 14, 331-332. 
bioRxiv preprint doi: https://doi.org/10.1101/2021.04.14.437159; this version posted April 14, 2021. The copyright holder for this preprint (which was not certified by peer review) is the author/funder, who has granted bioRxiv a license to display the preprint in perpetuity. It is made available under aCC-BY-NC-ND 4.0 International license.

\section{Lamella in silico Clearing (LisC) Algorithm}
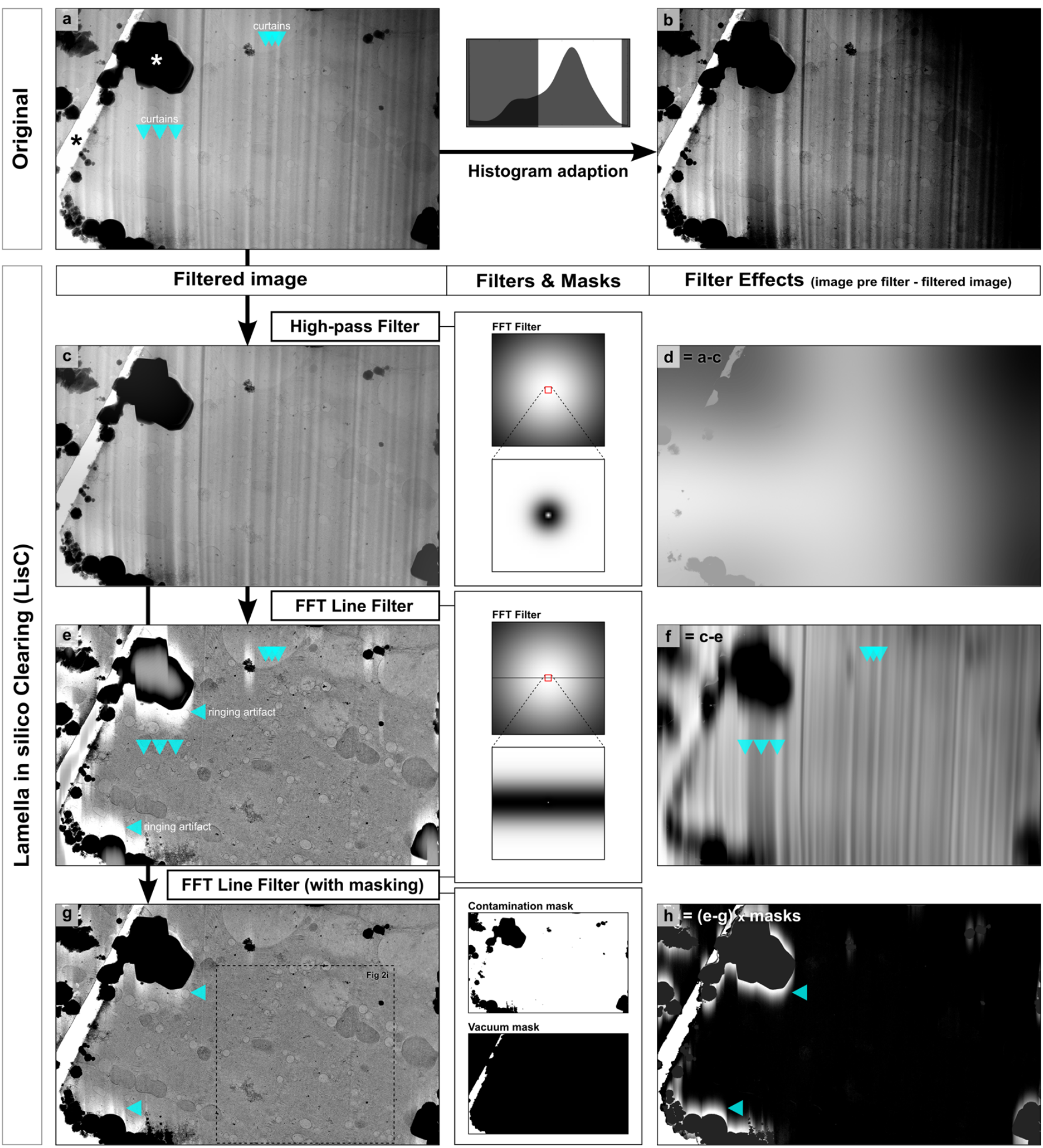

Extended Data Fig. 1: Lamella in-silico Clearing (LisC) algorithm.

The left column shows images before and after the different filtering steps. The middle column illustrates the filters and masks applied. The right column shows the effect of the filter, i.e. the image pre-filter minus the filtered image.

(a) Original overview micrograph of a lamella showing typical cryo-FIB milling imperfections such as 'curtains' (blue downwards arrows), i.e. local stripe-like variations in thickness, as well as long-range thickness differences over the whole lamella. These medium- and low-frequency thickness variations cause strong contrast alterations and make it difficult to identify biological structures in the lamella. A white asterisk marks ice contamination on top of the lamella, and a black asterisk marks the vacuum region, which can be seen through a crack in the lamella. (b) These artifacts become more pronounced if contrast is increased. (c) A high-pass filter removes the low frequency brightness modulation caused by the long-range thickness variations. The filter is shown in Fourier space in the box 'High-pass Filter'. A red box marks the region magnified below. (d) Difference of the highpass filtered image and the original: $(d)=(a)-(c)$. (e) The anisotropic, unidirectional curtains are efficiently removed (blue down arrows) by a line mask in Fourier space (see box 'FFT Line Filter') perpendicular to the direction of the curtains. A red box marks the region magnified below. The very strong contrast gradients between the lamella and ice crystal contamination or the vacuum regions marked by asterisks in (a) cause ringing artifacts (blue lateral arrows). ( $f$ ) Difference of the FFT line-filtered image and the high-pass filtered image: $(f)=(c)-(e)$. The filter efficiently removes curtains without affecting biological structures in the lamella. (g) The ringing artifacts shown in (e) can be strongly reduced by applying masks (see box 'FFT Line Filter (with masking)') to set the pixel values of the contamination and vacuum regions to a local gray value average before FFT line filtering. Lastly, the pixel values in the masked regions are set to 0 (contamination) and 256 (vacuum), respectively. The structural features of the tissue can be clearly discerned, as annotated in the area of this lamella shown in Fig. 2i (white box). (h) Difference of the masked vs. the unmasked FFT line-filtered image. The pixel values in the masked regions are set to 0 (contamination) and 256 (vacuum): $(\mathrm{h})=[(\mathrm{e})-(\mathrm{g})]$ x masks. The LisC algorithm is publicly available (https://github.com/FJBauerlein/LisC Algorithm) as a macro for Fiji. See also Supplementary Video 2. 
bioRxiv preprint doi: https://doi.org/10.1101/2021.04.14.437159; this version posted April 14, 2021. The copyright holder for this preprint (which was not certified by peer review) is the author/funder, who has granted bioRxiv a license to display the preprint in perpetuity. It is made available under aCC-BY-NC-ND 4.0 International license.

Nervous Tissue

(Peripheral nervous system: Peripheral nerve)
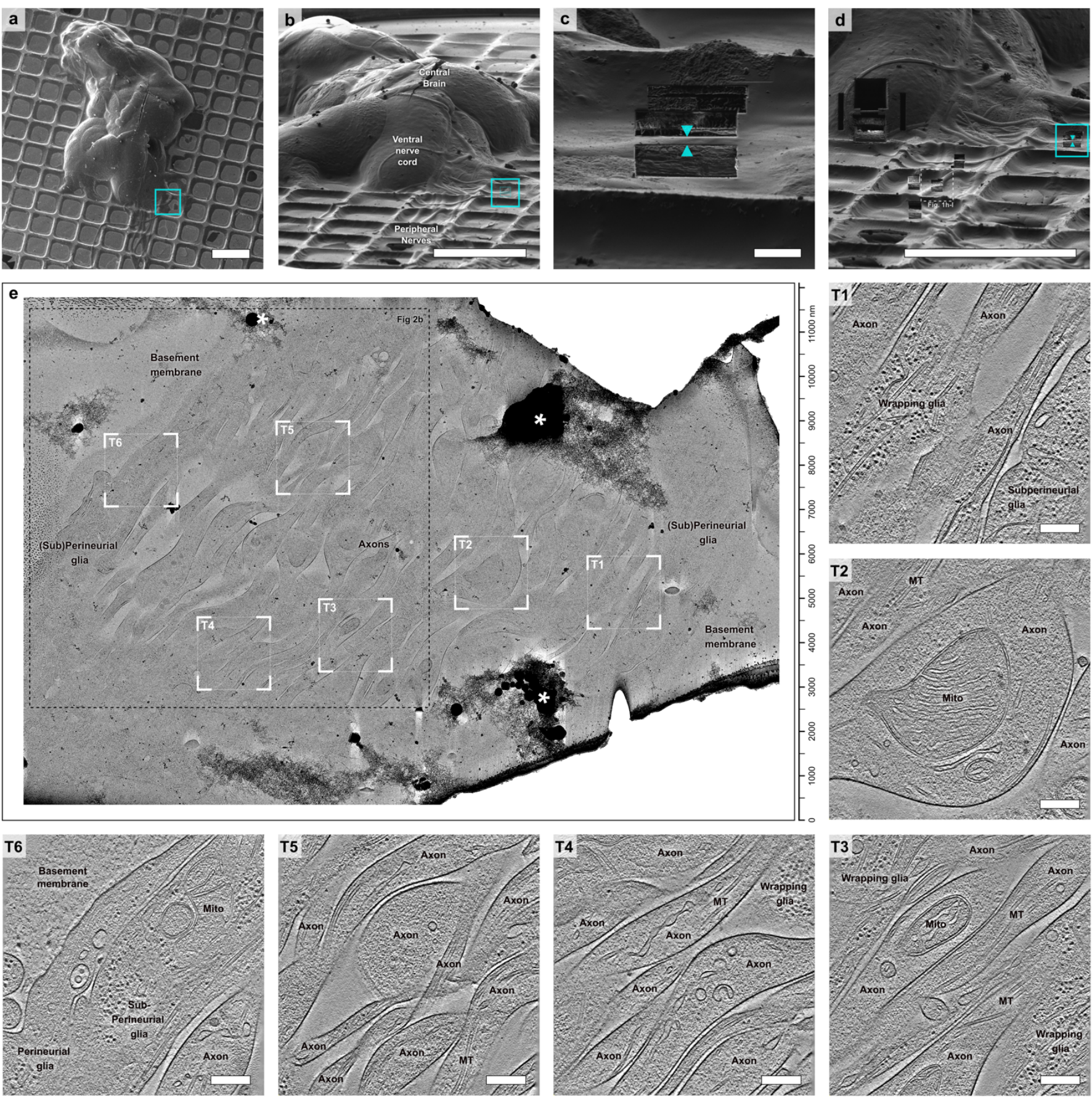

\section{Extended Data Fig. 2: Cryo-FIB lamella preparation of nervous tissue for cryo-ET imaging.}

(a) Top-view cryo-SEM image of the Drosophila cephalic complex shown in Fig. 1g and Fig. 2a. (b) Cryo-FIB-induced secondary electron side view of (a). (c) Preparation of the lamella shown in Fig. $2 \mathrm{~b}$ on a peripheral nerve at the location marked by a blue rectangle in (b). The lamella is indicated by blue arrows. (d) Cryo-FIB overview of the tissue with the final $\sim 150 \mathrm{~nm}$ thick lamella (blue box). (e) Cryo-TEM overview of the final lamella, visualizing parallel axons, sub-perineurial and perineurial glia, delimited by the basement membrane. The image was filtered using the LisC algorithm. The area of the lamella shown in Fig. $2 \mathrm{~b}$ is indicated by a black box. Tomograms were acquired in the regions marked by white boxes. (T1-T6) $1.7 \mathrm{~nm}$-thick slices of the tomograms recorded in the regions marked in (e). Mito: mitochondrion; MT: microtubule. T6 is also shown in Fig. 2c, $d$ and Supplementary Video 3 with its corresponding 3D rendering. Scale bars: $200 \mu \mathrm{m}(\mathrm{a}, \mathrm{b}, \mathrm{d}), 10 \mu \mathrm{m}$ (c), $250 \mathrm{~nm}$ (T1-T6). 
bioRxiv preprint doi: https://doi.org/10.1101/2021.04.14.437159; this version posted April 14, 2021. The copyright holder for this preprint (which was not certified by peer review) is the author/funder, who has granted bioRxiv a license to display the preprint in perpetuity. It is made available under aCC-BY-NC-ND 4.0 International license.

Epithelium

(Malpighian tubules)
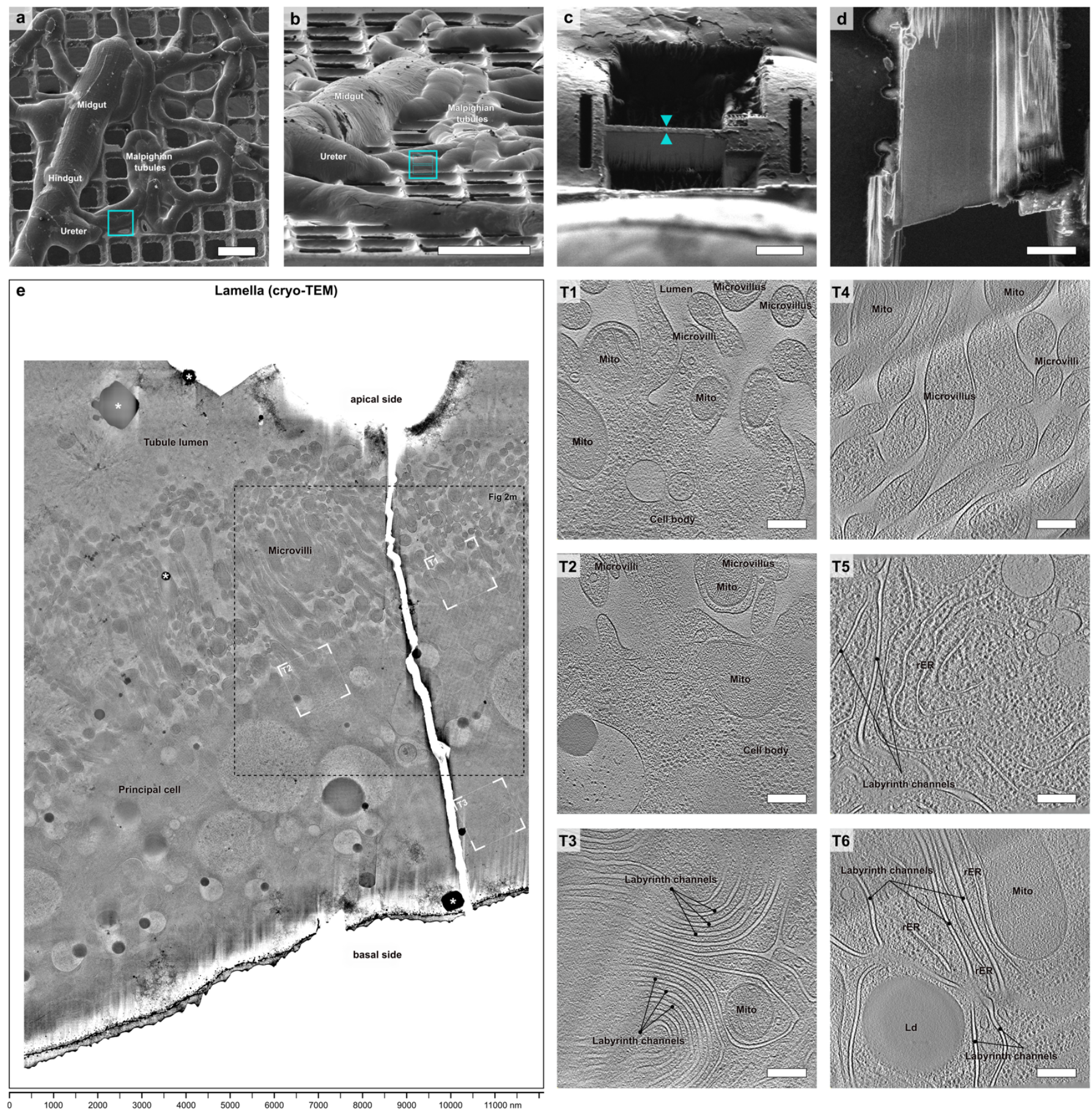

\section{Extended Data Fig. 3: Cryo-FIB lamella preparation of epithelial tissue for cryo-ET imaging.}

(a) Top-view cryo-SEM image of the Drosophila Malpighian tubules shown in Fig. 2I. (b) Cryo-FIB-induced secondary electron side view of (a). (c) Preparation of the lamella shown in Fig. $2 \mathrm{~m}$ on a Malpighian tubule at the location marked by a blue rectangle in (b). The lamella is indicated by blue arrows. (d) Cryo-SEM image of the final lamella. (e) Cryo-TEM overview of the final lamella, visualizing a principal cell from the basal to the apical pole with multiple microvilli emerging into the tubule lumen. The image was filtered using the LisC algorithm. The area of the lamella shown in Fig. $2 \mathrm{~m}$ is indicated by a black box. Tomograms were acquired in the regions marked by white boxes. (T1-T3) $1.7 \mathrm{~nm}$-thick slices of the tomograms recorded in the regions marked in (e). T1 is also shown in Fig. 2n, o and Supplementary Video 6 with its corresponding 3D rendering. (T4-T6) 1.7 nm-thick slices of the tomograms recorded on another lamella. Ld: lipid droplet; Mito: mitochondrion; rER: rough endoplasmic reticulum. Scale bars: $200 \mu \mathrm{m}$ (a, b), $10 \mu \mathrm{m}$ (c, d), $250 \mathrm{~nm}$ (T1-T6). 